\title{
Treat-ability of Manihot esculenta Peel Extract as Coagulant Aid for Stabilised Leachate
}

\author{
Siti Nor Aishah Mohd-Salleh¹, Nur Shaylinda Mohd-Zin ${ }^{1 *}$, Norzila Othman", \\ Yashni Gopalakrishnan ${ }^{1}$ and Norshila Abu-Bakar ${ }^{1,2}$ \\ ${ }^{1}$ Faculty of Civil Engineering and Built Environment, Universiti Tun Hussien Onn Malaysia, 86400 Parit Raja \\ Batu Pahat, Johor, Malaysia \\ ${ }^{2}$ Department of Civil Engineering, Politeknik Sultan Abdul Halim Mu'adzam Shah, Bandar Darulaman, \\ 06000 Jitra, Kedah, Malaysia
}

\begin{abstract}
Agro-waste can be commercialised into another useful product such as natural coagulant for wastewater treatment. The purpose of this study was to quantify the ability of agro-waste (Manihot esculenta peel extract (MEP)) as an aid alongside the utilisation of chemical coagulant (polyaluminium chloride (PAC)) based on the removal percentages of selected parameters at the optimum coagulant dosage and $\mathrm{pH}$ of stabilised leachate. Series of jar tests were used to compare the leachate treatments using single and the dual coagulant of PAC and MEP with respective standard methods to analyse the removal parameters, i.e., Colorimetric (APHA Method:5220 C, HACH Method:8000) for chemical oxygen demand (COD), Conductimetric (APHA Method: 4500-N, HACH Method: 8038) for ammonia nitrogen (AN), Nephelometric (APHA Method:2130) for turbidity, Spectrophotometric (APHA Method: 2120 B, HACH Method: 8025) for colour, and Gravimetric (APHA Method:2540 D, HACH Method:630) for suspended solids (SS). Leachate treatment using the application of single PAC coagulant at the optimum conditions of $3,750 \mathrm{mg} / \mathrm{L}$ dosage and $\mathrm{pH} 6.0$ of leachate managed

ARTICLE INFO

Article history:

Received: 10 February 2021

Accepted: 03 May 2021

Published: 31 July 2021

DOI: https://doi.org/10.47836/pjst.29.3.36

E-mail addresses:

sitinoraishah.salleh@gmail.com (Siti Nor Aishah Mohd-Salleh) nursha@uthm.edu.my (Nur Shaylinda Mohd-Zin) norzila@uthm.edu.my (Norzila Othman)

yashni_g@yahoo.com (Yashni Gopalakrishnan)

norshilaabubakar@yahoo.com (Norshila Abu-Bakar)

* Corresponding author to remove about $54.1 \%, 28 \%, 91.1 \%$, $98 \%$, and $98 \%$ for COD, AN, turbidity, colour, and SS, respectively. Meanwhile, by using dual coagulant at the optimum dosages of $3,500 \mathrm{mg} / \mathrm{L}(\mathrm{PAC})$ and 250 $\mathrm{mg} / \mathrm{L}$ (MEP), and $\mathrm{pH} 7.0$ of leachate, the treatment achieved higher removal except for the colour parameter. The final removal outcomes of this study were $58.3 \%$ of COD,
\end{abstract}


$34 \%$ of AN, $96.9 \%$ of turbidity, $92.1 \%$ of colour, and $99 \%$ of SS. The application of MEP as coagulant aid also managed to reduce the aluminium (Al) content in PAC dosage from $577.5 \mathrm{mg} / \mathrm{L}$ to $539.0 \mathrm{mg} / \mathrm{L}$ without affecting much of its efficiency.

Keywords: Coagulation-flocculation; jar test; natural coagulant; polyaluminium chloride; removal efficiency

\section{INTRODUCTION}

The percolation of rainwater through the degraded solid waste in the open landfill has resulted in the generation of leachate (Aziz et al., 2015). According to its classification, the composition of leachate may contain loads of toxic elements, which are harmful to the environment. The ignorance to treat leachate through proper disposal also could cause unpleasant pollution to receiving waters such as ground aquifers (Kamaruddin et al., 2015). The contents of chemical oxygen demand (COD), ammonia nitrogen (AN), and heavy metals are among a few of most environmental threats that become the significant considerations for leachate to be treated (Yusoff \& Zuki et al., 2015). COD is a chemical indicator that indicates the required oxygen to oxidise soluble and suspended organic matter. The high concentration of COD signs the degradation of the dissolved oxygen levels in water bodies. Meanwhile, the high level of AN can cause toxicity to aquatic life and human beings when the leachate leaks to the water resources (Mehmood et al., 2009). For instance, the villagers around Simpang Renggam's landfill site (SRLS) are jeopardised due to the exposure of contaminated water sources with high levels of AN. The untreated AN also becomes the main factor of reduced performances for biological treatments, dissolved oxygen reduction, and speeded up eutrophication in surface water (Aziz et al., 2015). Meanwhile, the high concentrations of suspended solids (SS), turbidity, and colour would eventually result in the poor aesthetic quality of the water (Wang et al., 2017).

Physical and chemical treatments such as the coagulation-flocculation (CF) process using jar test with the help of coagulating agents are favoured for the treatment of stabilised leachate due to its characteristics (Syafalni et al., 2012). In the CF treatment, the usage of effective coagulants is important. In this study, to tackle the drawbacks of chemical coagulant, the raw Manihot esculenta peel extract (MEP) peel is used and recycled as a natural coagulant aid to treat stabilised leachate. The peels were obtained from a chip's factory at Parit Raja, Johor, Malaysia. MEP may have been used as a coagulant aid in water and wastewater treatment, but MEP is never used for leachate treatment to the best of our knowledge. The chemical analysis of MEP has verified its competence as a natural coagulant through the existence of polysaccharides form of sugars (holocellulose and starch). Besides, the existence of functional groups (carboxyl, hydroxyl, and amino groups) from pectin, cellulose, and amino acids may also have cogency as flocculating agent (Mohd-Salleh et al., 2020a; Asharuddin et al., 2017). Asharuddin et al. (2018) used the same source of coagulant and alum as a dual coagulant to remove turbidity from dam 
water and achieved $91.47 \%$ removal. The MEP as the natural coagulant used in this study is made and developed from scratch without any chemical modification. Therefore, the purpose of this study was to quantify the ability of agro-waste (MEP) as an aid alongside the utilisation of chemical coagulant (PAC) based on the removal percentages of COD, AN, turbidity, colour and SS at the optimum coagulant dosage and $\mathrm{pH}$ of stabilised leachate. Basically, this study attempts to develop a green coagulant aid for the treatment of highstrength polluted wastewater. The effort of the study is also relevant as the developed natural coagulant could emphasise more usage of agro-waste as a natural material and give benefits to low social communities. This approach aims to increase the recycling and recovery rate of waste while improving the management of landfills to reduce the amount of waste and pollution. Furthermore, the findings would be useful for conserving human health and the environment as the consequence of the treatment of landfill leachate. In the dimension of economic development, this study would assist in sustainable energy for drivers and enablers and increasing innovation and productivity to the next level in the imperatives by focusing on natural coagulants and landfill leachate. Specifically, this study may also be a jumping-off point towards researchers, through the optimisation of leachate $\mathrm{pH}$ and dosages of PAC and MEP as a guideline to select a suitable condition range for leachate treatment with better removal percentages of respective contaminants in the future.

\section{MATERIALS AND METHODS}

\section{Leachate Sampling}

The leachate sample was taken from the Simpang Renggam landfill site (SRLS) (1 ${ }^{\circ} 53^{\prime} 41$ "N 103'22’35" E). SRLS is built in 1996 and still operating up to 2019 with 6 hectares in total size. As for now, the landfill is closed to focus on the treatment of left leachate. Approximately 250 tons of solid wastes were disposed into SRLS daily during its operation, which was over the limit practice. Based on the latest leachate characterisation study done by Mohd-Salleh et al. (2020b) and Zailani et al. (2018) that used the leachate samples taken from the same study area, the landfill was validated to generate stabilised leachate.

\section{Preparation of Manihot Esculenta Extract Peel Coagulant and Stock Solution}

Manihot esculenta peels (MEP) were collected from the chip's factory at Parit Raja, Johor, Malaysia. There is no cost to produce this natural coagulant because it is an agro-waste taken from the chip's factory for free. On the same day, upon arrival in the laboratory, the peels were separated from the big tubers and washed with tap water to remove the attached soils and impurities. The preparation of starch powder from the peels was according to the study done by Asharuddin et al. (2017) and Mohd-Salleh et al. (2020a). The brown peels were expelled, and only the white flesh from the cortex was scratched using a scratcher. The 
white flesh was blended using a domestic blender with distilled water. Next, the white flesh solution was filtered using a muslin cloth to filter the flesh waste. The blended white flesh was settled down for 24 hours, and the excess distilled water was rinsed out. The sticky blended white flesh was spread onto a tray and sundried until completely dry. Finally, the dried white flesh was smashed into a fine powder and stored in a tight container at room temperature. Figures 1 and 2 show the peels and their powder form. The stock solution of MEP was made in a concentration of $1 \%$ by diluting 1 gram of MEP into $100 \mathrm{~mL}$ of distilled water. A preliminary study was done to select the optimum concentration of MEP between $0.5 \%, 1 \%, 3 \%, 5 \%$, and $7 \%$ in treating leachate, of which $1 \%$ of MEP had shown satisfactory removal (Mohd-Salleh et al., 2020a). Thus, it was used in this study.

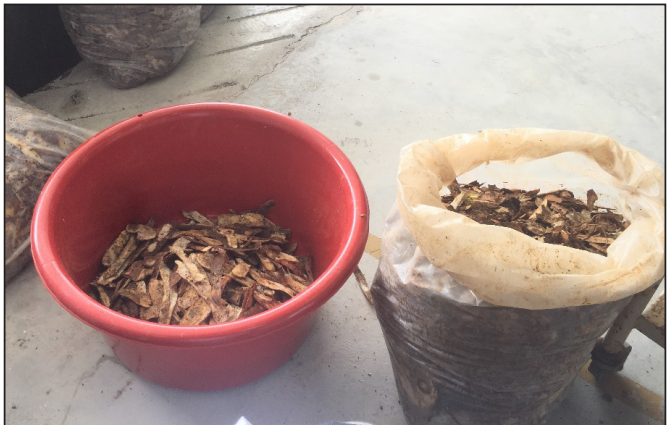

Figure 1. Manihot esculenta peels

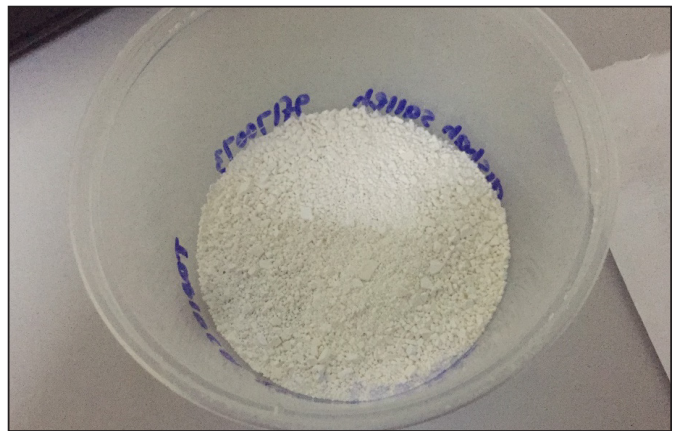

Figure 2. Powder form of MEP extract

\section{Preparation of Polyaluminium Chloride Stock Solution}

Polyaluminium chloride (R\&M brand) was purchased from the local laboratory supplier that cost $\$ 15$ per bottle. The preparation of PAC's stock solution was done by following the methodology of Mohd-Salleh et al. (2018) and Ni et al. (2015) that used 10\% of PAC. The coagulant needed to be prepared freshly; thus, it was prepared on the same day as the jar test for the CF process. To make a 10\% concentration of the stock solution, 10 grams of PAC were weighed and diluted into $100 \mathrm{~mL}$ of distilled water. The compound formula for $\mathrm{PAC}$ is $\mathrm{Al}_{2} \mathrm{Cl}(\mathrm{OH})$ with total $174.75 \mathrm{~g} / \mathrm{m}$ of molar mass $(\mathrm{Al}=26.982, \mathrm{O}=16, \mathrm{H}=1, \mathrm{Cl}=35.45)$.

\section{Experimental Procedure}

The CF experiments were performed in a conventional jar-test apparatus (VELP-Scientifica, Model: J LT6, Italy) comprising six paddle rotors $(2.5 \mathrm{~cm} \times 7.5 \mathrm{~cm})$, equipped with 6 beakers of $1 \mathrm{~L}$ each. The operating conditions of the jar test in this study were according to the study of Shaylinda et al. (2014). Two mixing stages were applied, i.e., rapid mixing at 200 revolutions per minute (rpm) for 4 minutes and slow mixing at $30 \mathrm{rpm}$ for 15 minutes. The time and speed for rapid and slow mixings were set with an automatic controller. The settling process was set for 30 minutes. The volume of the leachate sample used in the 
study was $500 \mathrm{~mL}$ (Zainol et al., 2011). In the jar test of the CF process, two factors were considered in determining the optimum treatment process, i.e., the coagulant dosage and leachate $\mathrm{pH}$ by dual and single coagulants of PAC and MEP.

In the $\mathrm{CF}$ treatment process, by using a single coagulant, a range of coagulant dosages of single MEP and PAC would be added into the respective altered $\mathrm{pH}$ of the leachate sample, right before the rapid mixing started. While for the treatment process using a dual coagulant, a range of coagulant dosage of MEP was added in the second stage of flocculation. The idea of dual coagulant was similar to the double dosage of different coagulants in one treatment. The dosage of PAC was added before the rapid mixing started, while the addition of MEP was done before the slow mixing of the jar test. The $\mathrm{pH}$ of the leachate sample was altered by using $1 \mathrm{~N}$ hydrochloric acid $(\mathrm{HCl})$ and $1 \mathrm{~N}$ sodium hydroxide $(\mathrm{NaOH})$ to obtain the desired $\mathrm{pH}$ 3.0-10.0 range. The experiments were carried out based on the conventional optimisation method of the one-factor-at-a-time (OFAT) method, which involved the try and error practices (Shaylinda et al., 2014).

\section{Optimisation of Coagulant Dosage and Leachate pH}

The selected range of dosages in leachate treatment by using a single PAC coagulant was from 2,250 mg/L to 4,500 mg/L (Mohd-Salleh et al., 2018). This dosage range was decided based on the preliminary study of dosage optimisation by using macro and micro ranges of coagulant dosages. While for PAC application in dual coagulant, the optimum dosage obtained from the CF was used as a constant factor while varying the dosage of MEP. For the dosage of $1 \%$ MEP as a coagulant aid, the dosages used were $50 \mathrm{mg} / \mathrm{L}-500$ $\mathrm{mg} / \mathrm{L}$ (Mohd-Salleh et al., 2020a). Again, this range was chosen from a preliminary study to decide the appropriate MEP range dosage to aid in the CF process using dual coagulant.

The optimisation of dosage was carried out first by altering the $\mathrm{pH}$ of the leachate sample into $\mathrm{pH}$ 7.0. It was selected due to its neutral properties that are desired in most treatments. After the best dosage was obtained, the $\mathrm{pH}$ optimisation was taken place by adjusting the $\mathrm{pH}$ from 3.0 to 10.0. In the first dosage optimisation of PAC and MEP in this study, the amount of single optimum PAC at 3,750 mg/L was used as a constant dosage following the study of Mohd-Salleh et al. (2018). Consequently, the different MEP dosages started from $50 \mathrm{mg} / \mathrm{L}$ to $500 \mathrm{mg} / \mathrm{L}$ was used as the coagulant aid. To achieve this, the $\mathrm{pH}$ of the leachate sample and the PAC dosage were remained constant at $\mathrm{pH} 7.0$ and 3,750 $\mathrm{mg} / \mathrm{L}$ dosage, respectively. The optimum conditions of these factors and the treatments' efficiency would be determined by the highest removal percentages on COD, AN, turbidity, colour, and SS. After accomplishing the jar tests, supernatant samples were withdrawn from the beaker by using a plastic syringe from the point located about $3 \mathrm{~cm}$ from the surface for the analysis and kept into another bottle. The analysis was done within the next 5 minutes after the settling process to prevent any changes in the characteristics of 
the treated leachate samples with respective standard methods to analyse the removal parameters, i.e., Colorimetric (APHA Method:5220 C, HACH Method:8000) for COD, Conductimetric (APHA Method: 4500-N, HACH Method: 8038) for AN, Nephelometric (APHA Method:2130) for turbidity, Spectrophotometric (APHA Method: 2120 B, HACH Method: 8025) for colour, and Gravimetric (APHA Method:2540 D, HACH Method:630) for SS. The measurement of all parameters was also done in the triplicate analysis by following the standard method of water and wastewater (APHA, 2017) to come out with the mean readings. The formula to calculate the removal percentage was based on Equation 1.

$$
\text { Percentage removal }(\%)=\frac{\text { Initial concentration-Final concentration }}{\text { Initial concentration }} \times 100
$$

Meanwhile, Equation 2 below is the calculation for the Al content in the PAC dosage.

$$
\begin{aligned}
10 \%= & (10 \mathrm{~g} / 100 \mathrm{~mL}) \times(1,000 \mathrm{mg} / 1 \mathrm{~g}) \times(1,000 \mathrm{~mL} / 1 \mathrm{~L}) \\
= & 100,000 \mathrm{mg} / \mathrm{L} \\
= & (100,000 \mathrm{mg} / \mathrm{L})(\mathrm{X})=(3,750 \mathrm{mg} / \mathrm{L}) \times(500 \mathrm{~mL}) \\
& \quad \mathrm{X}, \mathrm{V} 1=18.75 \mathrm{~mL}
\end{aligned}
$$

Dosage of $\mathrm{Al}$ in $3,750 \mathrm{mg} / \mathrm{L}$ of $\mathrm{PAC}$

$$
\begin{aligned}
& =(1.54 \mathrm{~g} / 100 \mathrm{~mL}) \times(1,000 \mathrm{mg} / 1 \mathrm{~g}) \times(1,000 \mathrm{~mL} / 1 \mathrm{~L}) \\
& =15,400 \mathrm{mg} / \mathrm{L} \\
& =(15,400 \mathrm{mg} / \mathrm{L})(18.75 \mathrm{~mL})=(X) \times(500 \mathrm{~mL}) \\
& \qquad X=577.5 \mathrm{mg} / \mathrm{L} \text { of Al }
\end{aligned}
$$

\section{RESULTS AND DISCUSSION}

\section{Coagulation-flocculation Treatment Process of Leachate Using Dual Coagulant of PAC and MEP}

Effect of PAC and MEP Dosages. The ability of MEP as a coagulant aid in the treatment of stabilised leachate is carried out first by pairing it with PAC in the first optimisation process. Figure 3 shows the outcome of dosages optimisation of PAC and MEP in term of removal percentages of respective parameters. Using this combination of a primary coagulant of PAC and a coagulant aid, pleasing results were given even though at the minimal dosage of MEP. The major removal was done by the PAC coagulant itself since the high dosage was added. Based on the observations of Figure 3, the removal outcomes were high, especially for turbidity, colour, and SS parameters. Increasing the MEP dosage 


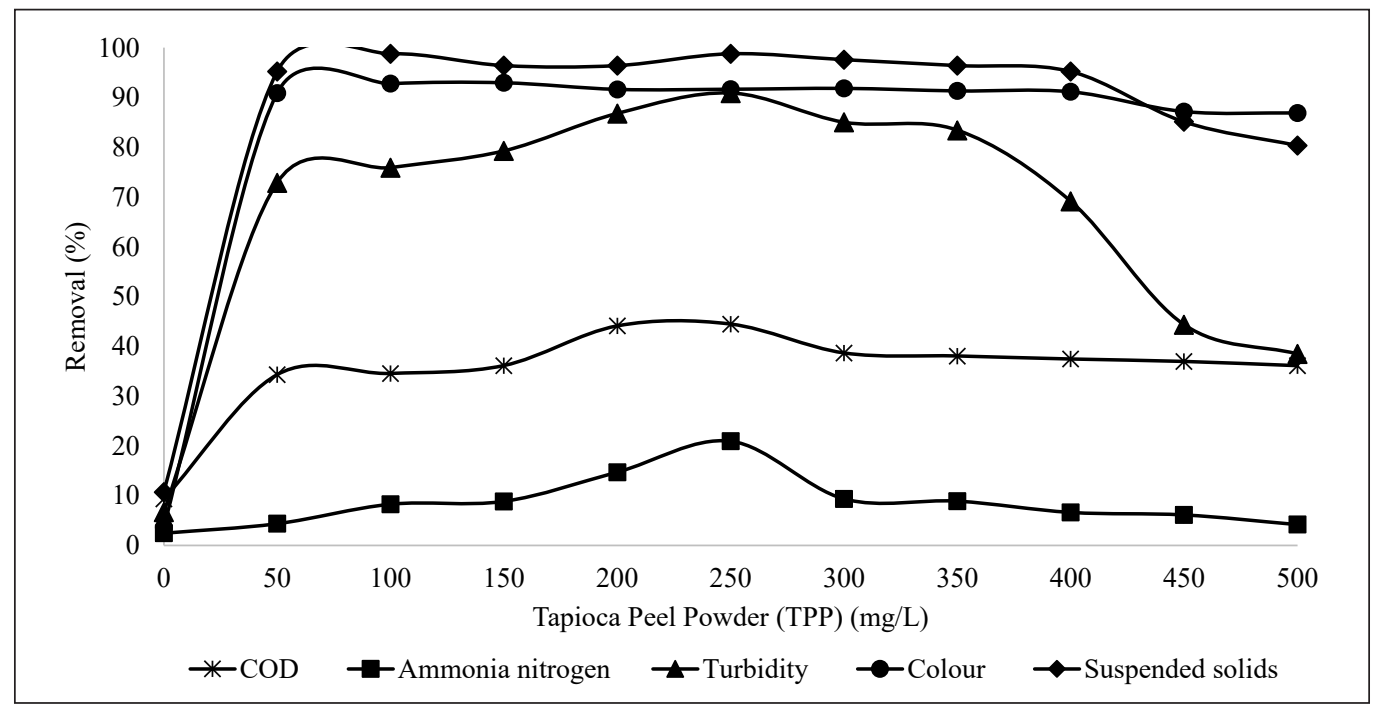

Figure 3. Dual coagulant at pH 7.0 with PAC (3,750 mg/L) and MEP (50-500 mg/L)

did not significantly affect the turbidity, colour, and SS removal, but rather it resulted in a linearly constant removal pattern.

The removal for colour and SS at all MEP dosages was quite satisfying by achieving more than $80 \%$ removal. However, there was a bit of fluctuating removal for the turbidity parameter, especially at the final dosages range. This might be due to the high dosage of MEP that caused the addition of turbidity in the leachate sample. The highest elimination obtained by COD, AN, and turbidity was obvious to happen at $250 \mathrm{mg} / \mathrm{L}$ of MEP by removing $44.5 \%, 20.9 \%$, and $90.9 \%$ removal, respectively. Thus, according to this, 250 $\mathrm{mg} / \mathrm{L}$ was decided as the optimum MEP dosage, with the removal of $44.5 \% \mathrm{COD}, 20.9 \%$ AN, and $90.9 \%$ turbidity, $91.7 \%$ colour, and $98.8 \%$ SS. For the next optimisation, by using the reduced optimum amount of MEP dosage at $250 \mathrm{mg} / \mathrm{L}$, the PAC dosage was varied again to verify the optimum dosage that happened at $3,750 \mathrm{mg} / \mathrm{L}$. Figure 4 shows the removal results using PAC dosage varied from $500 \mathrm{mg} / \mathrm{L}$ to $5,000 \mathrm{mg} / \mathrm{L}$, respectively.

Based on the evaluations of Figure 4, the removal of COD, turbidity, colour, and SS continued to increase as the dosage increased. However, the removals started to remain constant at the PAC dosage of 2,000 mg/L and decreased gradually at the dosage of 4,000 $\mathrm{mg} / \mathrm{L}$. While for AN, the removal was lower compared to another four parameters. It was noticeable that the elimination of AN was the highest at the dosage of 3,000 $\mathrm{mg} / \mathrm{L}$ and $3,500 \mathrm{mg} / \mathrm{L}$ with $33.4 \%$ and $33.8 \%$, respectively, just by having a $0.4 \%$ difference. For other parameters, the high removal could be observed at the dosage of 3,000 $\mathrm{mg} / \mathrm{L}$ and $3,500 \mathrm{mg} / \mathrm{L}$ as well, with a very close gap. At the dosage of 3,000 mg/L, the removal for all parameters was $55.9 \%$ of COD, 33.4\% of AN, $93.1 \%$ of turbidity, $96.3 \%$ of colour, and $99 \%$ of SS. While for $3,500 \mathrm{mg} / \mathrm{L}$, the achieved removals were $57.4 \%, 33.8 \%, 95.8 \%$, 


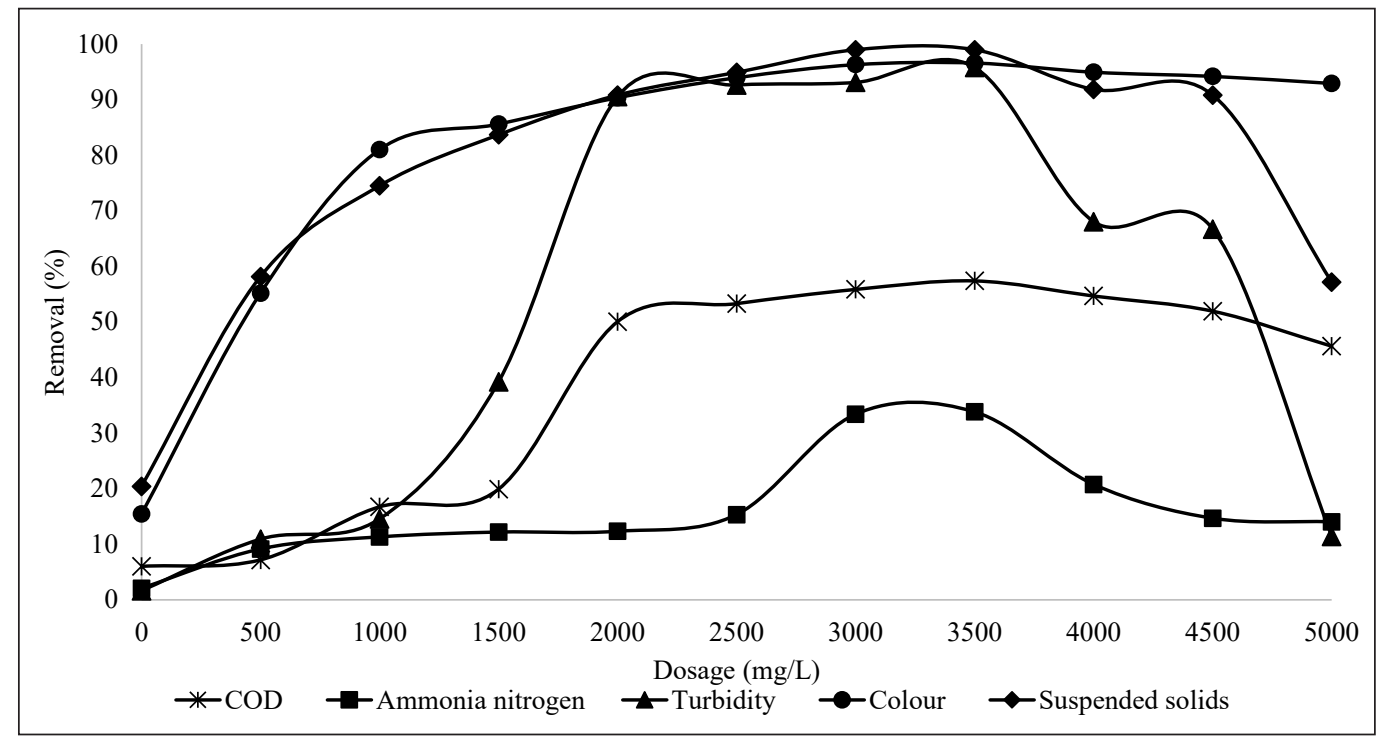

Figure 4. Dual coagulant at pH 7.0 with MEP (250 mg/L) and PAC (500-5,000 mg/L)

$96.6 \%$, and $99 \%$ for COD, AN, turbidity, colour, and SS, respectively. Thus, based on the removals, the PAC dosage of $3,500 \mathrm{mg} / \mathrm{L}$ was determined as the optimum PAC for dual coagulant, with the aid of optimum MEP dosage at $250 \mathrm{mg} / \mathrm{L}$. Hence, the optimum dosages of both PAC and MEP were obtained at 3,500 mg/L and $250 \mathrm{mg} / \mathrm{L}$, respectively, by applying the dosages at $\mathrm{pH} 7.0$ of leachate samples.

Effect of Leachate pH Using PAC and MEP Coagulants. The next optimisation was carried out to discover the optimum $\mathrm{pH}$ condition that worked best for the combination of PAC as primary coagulant and MEP as the coagulant aid in this study. The samples' $\mathrm{pH}$ was varied from $\mathrm{pH} 3.0$ to $\mathrm{pH} 10.0$ by using 3,500 mg/L PAC dosage and $250 \mathrm{mg} / \mathrm{L} \mathrm{MEP}$ dosage, as shown in Figure 5. Based on the CF process of dual coagulant in Figure 5, the removals of colour and SS were started quite high at $\mathrm{pH} 3.0$, but it decreased as the $\mathrm{pH}$ increased to $\mathrm{pH}$ 6.0. However, at $\mathrm{pH}$ 7.0, it rose again and became the highest reduction with $92.1 \%$ and $99 \%$ removals, respectively. The turbidity parameter was also observed to be effectively removed at $\mathrm{pH} 7.0$ with a $96.9 \%$ reduction. The removal for turbidity started low at $\mathrm{pH} 3.0$ with $18.8 \%$ elimination. Even though the removal for colour and SS at pH 3.0 was quite satisfying, the turbidity of the treated sample was not well eliminated. The high elimination was observed to be at $\mathrm{pH} 7.0$ and $\mathrm{pH} 8.0$ with $58.3 \%$ and $57.8 \%$, respectively, with less than 5\% difference for the removal of COD. Meanwhile, for AN, the elimination was high at both pH 6.0 and pH 7.0 with $35.5 \%$ and 34\% removal, respectively, with less than $5 \%$ difference. However, most of the highest elimination of parameters happened at the neutral $\mathrm{pH} 7.0$ of leachate samples. Therefore, it was decided that the dual coagulant 


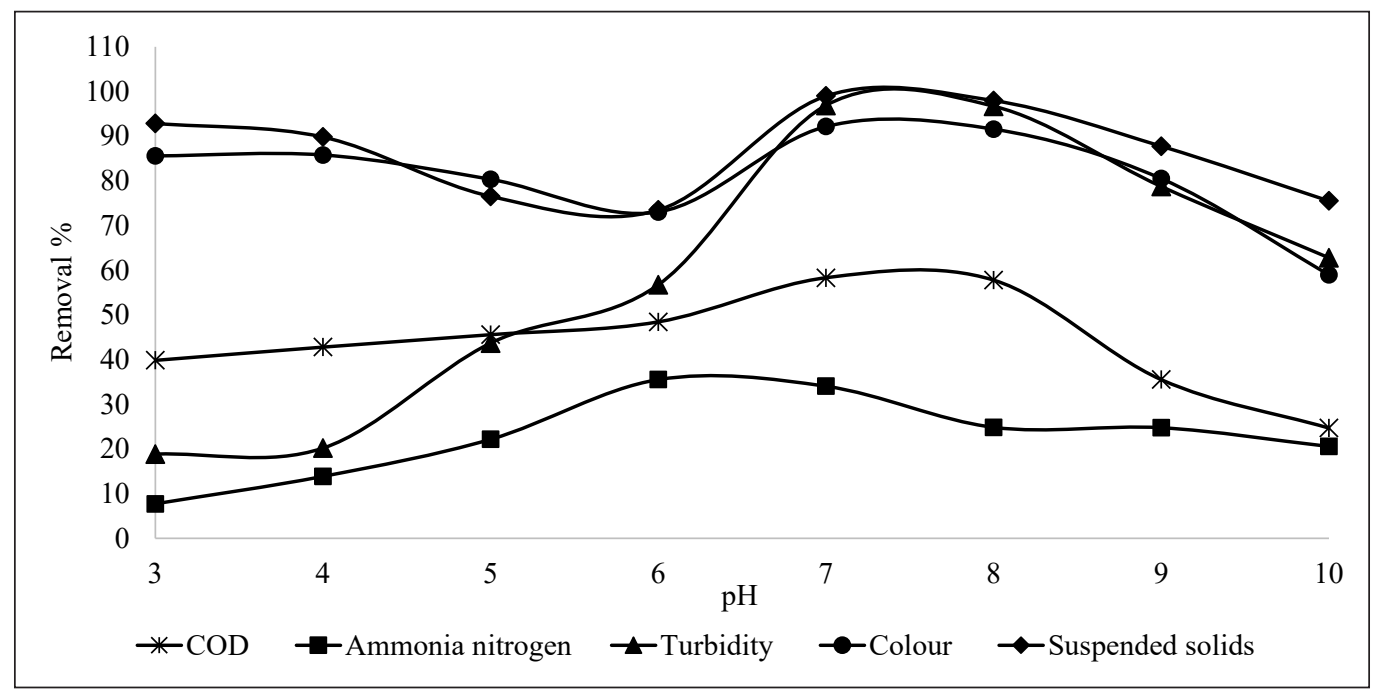

Figure 5. Dual coagulant of PAC (3,500 mg/L) and MEP (250 mg/L) at varied pH 3.0-10.0

worked effectively at $\mathrm{pH} 7.0$ by eradicating $58.3 \%$ of COD, $34 \%$ of AN, $96.9 \%$ of turbidity, $92.1 \%$ of colour, and $99 \%$ of SS as the finals results.

Performance Comparison of Dual Coagulant (PAC and MEP) With Previous Studies. The performance of dual coagulant in the present study was compared with the capability of other studies that utilised primary coagulant with a coagulant aid in treating the leachate sample. In dual coagulant practice, the inorganic coagulant such as PAC promotes the colloid destabilisation with the key mechanism of charge neutralisation. The addition of a polymer would act as the bridging agent in encouraging the small colloids to agglomerate together and become bigger and heavy flocs (Mohd-Salleh et al., 2020c; Awang \& Aziz, 2012). The matching pair of PAC and other natural coagulants as dual coagulants were investigated based on their performance to remove the respective contaminants in the comparison studies. The appropriate teaming would generate good achievements in the CF process, which was the highlight point in the significance studies of dual coagulant. It was such a good undertaking that many kinds of research had been made on the locally grown plants to diverge their function, such as being a sustainable coagulant for water and wastewater treatment.

Al-Hamadani et al. (2011) had studied the capability of PAC and psyllium husk as the dual coagulating agent of leachate treatment. They obtained the neutral $\mathrm{pH}$ of 7.2 as the ideal leachate $\mathrm{pH}$ with $400 \mathrm{mg} / \mathrm{L}$ of psyllium husk and 7,200 mg/L of PAC dosages with satisfying removals, i.e., $64 \%$ of COD, $90 \%$ of colour, and $96 \%$ of SS. The tobacco leaf (1000 $\mathrm{mg} / \mathrm{L}$ dosage) was also used as the coagulant aid by obtaining the apparent COD removal at $91 \%$ indeed with 1,500 mg/L dosage of PAC at pH 6.0 (Rusdizal et al., 2015). 
The result for the AN parameter (54\% removal) was also good enough to initiate the leaf as a competitive natural coagulant.

However, a bit lower removal was observed for physical parameters of turbidity and SS at $21 \%$ and $48 \%$, respectively (Rusdizal et al., 2015). Tobacco leaf could be classified as an anionic coagulant with $-3.57 \mathrm{mV}$ zeta potential, which had a higher negative charge than tapioca starch at $-0.56 \mathrm{mV}$ (Azizan et al., 2020; Rusdizal et al., 2015). The attraction of the opposite charges in the treated sample using tobacco leaves is possibly stronger than others; thus, it succeeded in removing the high percentages of organic contaminants (Rusdizal et al., 2015). The same starch source was also reported in the study of Asharuddin et al. (2018) to remove turbidity from dam water. The term used for the natural coagulant was cassava peel starch (CPS). It was used as an aid with alum and achieved a high turbidity removal with $91.47 \%$, at the optimum conditions of $\mathrm{pH} 9.0,7.5 \mathrm{mg} / \mathrm{L}$ of alum dosage, and $100 \mathrm{mg} / \mathrm{L}$ of CPS dosage. The addition of CPS in the treatment system also reduced about $50 \%$ of the alum dosage (Asharuddin et al., 2018). Hence, based on the comparison performance, it is proven that natural coagulant extracted from agro-waste like MEP has a positive effect on improving coagulation treatment.

Comparison of Treated Leachate Sample with EQA 2009. The final concentrations value of evaluated parameters in treated leachate using PAC and PAC+MEP coagulants and the Environmental Quality (Control of pollution from solid waste transfer station \& landfill) Regulation 2009 under the laws of Malaysia Environmental Quality Act 1974 are shown in Table 1. The CF treatment on $500 \mathrm{~mL}$ leachate sample using a single coagulant of PAC managed to remove about $54.1 \%$ of COD, $28.0 \%$ of AN, $91.1 \%$ of turbidity, $98.0 \%$ of colour, and $98.0 \%$ of SS, by employing $\mathrm{pH} 6.0$ of leachate and $3,750 \mathrm{mg} / \mathrm{L}$ of PAC dosage. Meanwhile, for the application of dual coagulant, the combination of 3,500 $\mathrm{mg} / \mathrm{L}$ (PAC), $250 \mathrm{mg} / \mathrm{L}$ (MEP) and $\mathrm{pH} 7.0$ of leachate achieved better removal except for colour parameter, with $57.4 \%$ of COD, $33.8 \%$ of AN, $95.8 \%$ of turbidity, $96.6 \%$ of colour, and $99.0 \%$ of SS. The comparison of removal percentages using PAC and PAC+MEP is tabulated in Table 2.

Table 1

Comparison of the final concentration of treated leachate with EQA 2009

\begin{tabular}{lccc}
\hline Parameter & Treated leachate with PAC & $\begin{array}{c}\text { Treated leachate with PAC } \\
+ \text { MEP }\end{array}$ & $\begin{array}{c}\text { Malaysia's EQA } \\
2009\end{array}$ \\
\hline COD (mg/L) & $1,157.6$ & 465.0 & 400.0 \\
AN (mg/L) & 816.3 & 417.5 & 5.0 \\
Turbidity (NTU) & 12.2 & 2.3 & n.a. \\
Colour (ADMI) & 144.2 & 191.18 & 100.0 \\
SS (mg/L) & 5.9 & 1.0 & 50.0 \\
\hline
\end{tabular}


Table 2

Comparison of the removal percentages between $P A C$ and $P A C+M E P$

\begin{tabular}{lcc}
\hline Parameter & Removal (\%) using PAC & Removal (\%) using PAC + MEP \\
\hline COD (mg/L) & 54.1 & 57.4 \\
AN (mg/L) & 28.0 & 33.8 \\
Turbidity (NTU) & 91.1 & 95.8 \\
Colour (ADMI) & 98.0 & 96.6 \\
SS (mg/L) & 98.0 & 99.0 \\
\hline Optimised conditions & $\mathrm{pH} 6.0$ of leachate & $\mathrm{pH} 7.0$ of leachate \\
& $3,750 \mathrm{mg} / \mathrm{L}(\mathrm{PAC})$ & $3,500 \mathrm{mg} / \mathrm{L}(\mathrm{PAC})+250 \mathrm{mg} / \mathrm{L}(\mathrm{MEP})$ \\
\hline
\end{tabular}

From this finding, it was observed that the superiority of the treatment possibly happened due to the high molecular weight of MEP that helped to stimulate the flocculation development. Simultaneously, the adsorption bridging mechanism influences the aggregation process due to the interaction of high-molecular-weight coagulant and natural polysaccharide composition with impurities in the leachate sample (Mohd-Salleh et al., 2020c; Li et al., 2015; Oladoja, 2016). Besides, the removal mechanism of charge neutralisation for the treatment using PAC was also expected to be superior to PAC+MEP, considering the higher dosage. This was because PAC would encounter hydrolysis activity that resulted in amorphous aluminium hydroxide $\mathrm{Al}(\mathrm{OH})_{3}$ (Aljuboori et al., 2015). Based on the comparison with local's regulations, only the SS parameter from both treatments complied with the discharge standard. Even though the other parameters did not meet the limit set by the local regulations, the outcome was reasonable by considering the sample used was the raw leachate, without any prior treatments at the landfill site.

\section{CONCLUSIONS}

In conclusion, based on the observations on the effectiveness of single coagulant PAC and dual coagulant (PAC + MEP), it could be denoted that the combination of PAC and MEP as the primary coagulant and the coagulant aid could enhance the removal of respective parameters, which was better than the performance of single coagulant of PAC alone. The treatability studies on stabilised leachate using 10\% PAC with the optimum conditions happened at $\mathrm{pH} 6.0$ and dosage $3,750 \mathrm{mg} / \mathrm{L}$. Meanwhile, the highlight findings were in the utilisation of both PAC and MEP, in the optimised conditions of $\mathrm{pH} 7.0,3,500 \mathrm{mg} / \mathrm{L}$ dosage of PAC, and $250 \mathrm{mg} / \mathrm{L}$ dosage of MEP, respectively, with a $6.7 \%$ reduction of $\mathrm{Al}$ content dosage from $577.5 \mathrm{mg} / \mathrm{L}$ of single PAC coagulant to $539 \mathrm{mg} / \mathrm{L}$ in dual coagulant. Thus, the new MEP coagulant was verified to offer the full role-play as a coagulant aid by producing a good synergistic effect together with the coagulating benefits from PAC. This was especially in obtaining the neutral $\mathrm{pH}$ and lower chemical dosage content as the ideal conditions for the treatment system. Overall, this study concluded a distinctive conclusion 
that natural coagulants isolated from agro-waste could also enhance the treatment of highly polluted wastewater like leachate, which most other scholars did not prefer for a treatment. It is desirable to have further research on green natural coagulants to improve leachate and wastewater treatments in the future.

\section{ACKNOWLEDGEMENTS}

This research was supported by Universiti Tun Hussien Onn Malaysia (UTHM) through TIER 1 Grant Vot H860.

\section{REFERENCES}

Al-Hamadani, Y. A. J., Yusoff, M. S., Umar, M., Bashir, M. J. K., \& Adlan, M. N. (2011). Application of psyllium husk as coagulant and coagulant aid in semi-aerobic landfill leachate treatment. Journal of Hazardous Materials, 190(1-3), 582-587. http://doi.org/10.1016/j.jhazmat. 2011.03.087

Aljuboori, A. H. R., Idris, A., Al-joubory, H. H. R., Uemura, Y., \& Abubakar, B. I. (2015). Flocculation behavior and mechanism of bioflocculant produced by Aspergillus flavus. Journal Environment Management, $150,466-471$.

APHA. (2017). Standard methods for the examination of water and wastewater (23rd Ed.). American Public Health Association.

Asharuddin, S. M., Othman, N., Shaylinda, M. Z. N., \& Tajarudin, H. A. (2017). A chemical and morphological study of cassava peel: A potential waste as coagulant aid. In MATEC Web of Conferences, 103(4), Article 06012. http://doi.org/10.1051/matecconf/201710306012

Asharuddin, S. M., Othman, N., Shaylinda, N., Zin, M., Tajarudin, H. A., Din, M. F., \& Kumar, V. (2018). Performance assessment of cassava peel starch and alum as dual coagulant for turbidity removal in dam water. International Journal of Integrated Engineering, 10(4), http://doi.org/10.30880/ijie.2018.10.04.029

Awang, N. A., \& Aziz, H. A. (2012). Hibiscus rosa-sinensis leaf extract as coagulant aid in leachate treatment. Journal of Applied Water Science, 2(4), 293-298. http://doi.org/10.1007/s13201-012-0049-y

Aziz, S. Q., Aziz, H. A., Bashir, M. J. K., \& Mojiri, A. (2015). Assessment of various tropical municipal landfill leachate characteristics and treatment opportunities. Global NEST Journal, 17(3), 439-450.

Azizan, M. O., Shaylinda, M. Z. N., Mohd-Salleh, S. N. A., Mohd-Amdan, N. S., Yashni, G., Fitryaliah, M. S., \& Afnizan, W. M. W. (2020). Treatment of leachate by coagulation-flocculation process using polyaluminum chloride (PAC) and tapioca starch (TS). In IOP Conference Series: Materials Science and Engineering, 736, Article 022029. http://doi:10.1088/1757-899X/736/2/022029

Kamaruddin, M. A., Yusoff, M. S., Aziz, H. A., \& Hung, Y. T. (2015). Sustainable treatment of landfill leachate. Journal of Applied Water Science, 5(2), 113-126. http://doi.org/10.1007/s13201-014-0177-7

Li, S., Lv, Y., \& Liu, Z. (2015). Preparation of composite coagulant of PFM-PDMDAAC and its coagulation performance in treatment of landfill leachate. Journal of Water Reuse and Desalination, 5(2), 177-188. http://doi.org/ 10.2166/wrd.2015.093 
Mehmood, M. K., Adetutu, E., Nedwell, D. B., \& Ball, A. S. (2009). In situ microbial treatment of landfill leachate using aerated lagoons. Journal of Bio resource Technology, 100(10), 2741-2744. http://doi. org/10.1016/j.biortech.2008.11.031

Mohd-Salleh, S. N. A., Mohd-Zin, N. S., Othman, N., Mohd-Amdan, N. S., \& Mohd-Shahli, F. (2018). Dosage and $\mathrm{pH}$ optimization on stabilized landfill leachate via coagulation-flocculation process. In MATEC Web of Conferences (Vol. 250, p. 06007). EDP Sciences. https://doi.org/10.1051/matecconf/201825006007

Mohd-Salleh, S. N. A., Shaylinda, M. Z. N., Othman, N., Yasni, G., \& Norshila, A. B. (2020a). Optimisation of tapioca peel powder as natural coagulant in removing chemical oxygen demand, ammonia nitrogen, turbidity, colour, and suspended solids from leachate sample. In Water and Environmental Engineering (pp. 69-86). UTHM Publishing.

Mohd-Salleh, S. N. A., Shaylinda, M. Z. N., Othman, N., Azizan, M. O., Yashni, G., \& Afnizan, W. M. W. (2020b). Sustainability analysis on landfilling and evaluation of characteristics in landfill leachate: A case study. In IOP Conference Series: Materials Science and Engineering, 736, Article 072002. https:// doi:10.1088/1757-899X/736/7/072002

Mohd-Salleh, S. N. A., Shaylinda, M. Z. N., Othman, N., Yasni, G., \& Norshila, A. B. (2020c). Coagulation performance and mechanism of a new coagulant (Polyaluminium chloride-tapioca peel powder) for landfill leachate treatment. Journal of Engineering Science and Technology, 15(6), 3709-3722.

Ni, F., He, J., Wang, Y., \& Luan, Z. (2015). Preparation and characterisation of a cost-effective red mud/ polyaluminum chloride composite coagulant for enhanced phosphate removal from aqueous solutions. Journal of Water Process Engineering, 6, 158-165.

Oladoja, N. A. (2016). Advances in the quest for substitute for synthetic organic polyelectrolytes as coagulant aid in water and wastewater treatment operations. Journal of Sustainable Chemistry and Pharmacy, 3, 47-58. http://doi.org/10.1016/j.scp.2016.04.001

Rusdizal, N., Aziz, H. A., \& Mohd-Omar, F. (2015). Potential use of polyaluminium chloride and tobacco leaf as coagulant and coagulant aid in post-treatment of landfill leachate. Avicenna Journal Environmental Health Engineering, 2(2), 1-5. http://doi.org/10.1007/978-3-7091-0693-8

Shaylinda, M. Z. N., Aziz, H. A., Adlan, M. N., Ariffin, A., Yusoff, M. S., \& Dahlan, I. (2014). Treatability study of partially stabilized leachate by composite coagulant (Pre-hydrolyzed iron and tapioca flour). International Journal of Scientific Research in Knowledge, 2(7), 313-319. http://doi.org/10.12983/ijsrk2014-p0313-0319

Syafalni, Lim, H. K., Ismail, N., Abustan, I., Murshed, M. F., \& Ahmad, A. (2012). Treatment of landfill leachate by using lateritic soil as a natural coagulant. Journal of Environmental Management, 112, 353-359. http:// doi.org/10.1016/j.jenvman.2012.08.001

Wang, B., Shui, Y., He, M., \& Liu, P. (2017). Comparison of flocs characteristics using before and after composite coagulants under different coagulation mechanisms. Journal of Biochemical Engineering, 121, 107-117. http://doi.org/10.1016/j.bej.2017.01.020

Yusoff, M. S., \& Zuki, N. A. M. (2015). Optimum of treatment condition for Artocarpus heterophyllus seeds starch as natural coagulant aid in landfill leachate treatment by RSM. Journal of Applied Mechanics and Materials, 802, 484-489. http://doi.org/10.4028/www.scientific.net/ AMM.802.484 
Zailani, L. W. M., Mohd-Amdan, N. S., \& Shaylinda, M. Z. N. (2018). Characterisation of leachate at Simpang Renggam landfill site, Johor, Malaysia. In IOP Conference Series: Earth and Environmental Science, 140(1), Article 012053. http://doi.org/10.1088/17551315/140/1/012053

Zainol, N. A., Aziz, H. A., Yusoff, M. S., \& Umar, M. (2011). The use of poly aluminum chloride for the treatment of landfill leachate via coagulation and flocculation processes. Research Journal of Chemical Sciences, 1(3), 34-39. 